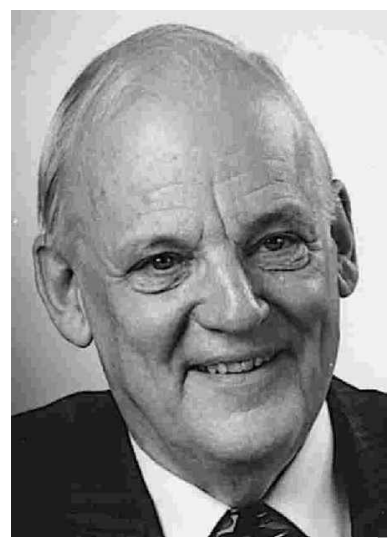

Gösta Samuelson gosta.samuelson@htu.se

\title{
Food warnings: a dilemma for scientists and the mass media
}

$\mathrm{I}$ n April this year a group of scientists at the University of Stockholm, together with toxicological scientists from the Swedish National Food Administration (NFA), called a press conference to present news on dangerous contents in commonly consumed food products.

The scientists had found high levels of acrylamide, a substance believed to cause cancer, in starch-rich foods prepared or processed at high temperatures. The Swedish media reported that high-risk foods included potato chips, French fries, crispbreads and fried potatoes. However, the research was performed on rats, not in humans, and although the results had been accepted for publication in a scientific journal, they had not yet been published. This situation is extraordinary: usually, research results are first discussed and debated among scientists, which was not the case before this remarkable early warning was issued.

The NFA has conducted studies on the content of acrylamide in different foods, which certainly is of utmost importance. The agency has a responsibility to inform the public about the results and possible consumption risks. However, the astonishing conclusion was that people should not change their consumption habits, despite the proposed risks. In my opinion, alarming and premature reports concerning dangers to health and particularly alarms over cancer risks are dangerous, even though they may be confirmed later. The public has now been confused, and the credibility of future alerts over food may not be taken seriously.

\section{Diet combined with physical activity: a key to better public health}

During the past few decades overweight and obesity have become an increasing problem in many countries all over the world. In Sweden overweight is increasing in children and young people, as well as in adults. At the same time diabetes is becoming more prevalent in both children and adults. Type II diabetes is now also being diagnosed in children.

The Swedish Nutrition Foundation arranged a symposium in Stockholm in November 2001: "Diet and physical activity - from research to practice in a Nordic perspective". The present issue of the Scandinavian Journal of Nutrition includes a collection of articles in Swedish, with English abstracts.

The articles cover both basic research and practical applications. Physical inactivity results in metabolic changes in the skeletal muscles, changes that contribute to insulin resistance, overweight and atherosclerosis. The mechanisms behind these changes arising from physical inactivity are described in this issue of the journal.

Physical exercise has positive effects on bone mass and bone density, resulting in a decreased risk of bone fractures, as well as on the metabolic syndrome. However, we do not know how physically active people actually are. We need more research about the effects of physical activity in health-promotion programmes, as well as guidelines concerning the duration and intensity of physical exercise.

In a debate article, Johan Faskunger and Erik Hemmingsson call for an increase in government spending on existing health-promotion programmes and courses, and research into nutrition and physical activity. The increased time spent in front of the television, playing computer games, in cars and on escalators at the expense of physical activity should be reduced.

Both an individual and a population approach is necessary to stop the escalating disease panorama caused by today's sedentary lifestyle. 